Prepared in cooperation with the

New York State Department of Environmental Conservation

\title{
Analysis of Pharmaceutical and Other Organic Wastewater Compounds in Filtered and Unfiltered Water Samples by Gas Chromatography/Mass Spectrometry
}

Open-File Report 2013-1297 



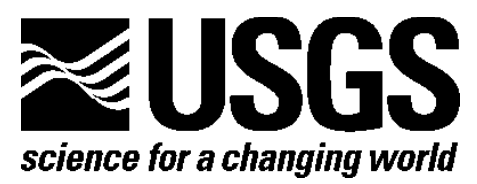

Prepared in cooperation with the

New York State Department of Environmental Conservation

\section{Analysis of Pharmaceutical and Other Organic Wastewater Compounds in Filtered and Unfiltered Water Samples by Gas Chromatography/Mass Spectrometry}

By Steven D. Zaugg, Patrick J. Phillips, and Steven G. Smith

Open File Report 2013-1297

U.S. Department of the Interior

U.S. Geological Survey 


\section{U.S. Department of the Interior \\ SALLY JEWELL, Secretary}

\section{U.S. Geological Survey \\ Suzette M. Kimball, Acting Director}

U.S. Geological Survey, Reston, Virginia: 2014

For more information on the USGS-the Federal source for science about the Earth,

its natural and living resources, natural hazards, and the environment-visit

http://www.usgs.gov or call 1-888-ASK-USGS

For an overview of USGS information products, including maps, imagery, and publications, visit $h$ ttp://www.usgs.gov/pubprod

To order this and other USGS information products, visit http://store.usgs.gov

Suggested citation:

Zaugg, S.D., Phillips, P.J., and Smith, S.G., 2014, Analysis of pharmaceutical and other organic wastewater compounds in filtered and unfiltered water samples by gas chromatography/mass spectrometry: U.S. Geological Survey Open-File Report 2013-1297, 24 p., at $h$ ttp://dx.doi.org/10.3133/ofr20131297.

Any use of trade, firm, or product names is for descriptive purposes only and does not imply endorsement by the U.S. Government.

Although this information product, for the most part, is in the public domain, it also may contain copyrighted materials as noted in the text. Permission to reproduce copyrighted items must be secured from the copyright owner.

ISSN 2331-1258 (online) 


\section{Contents}

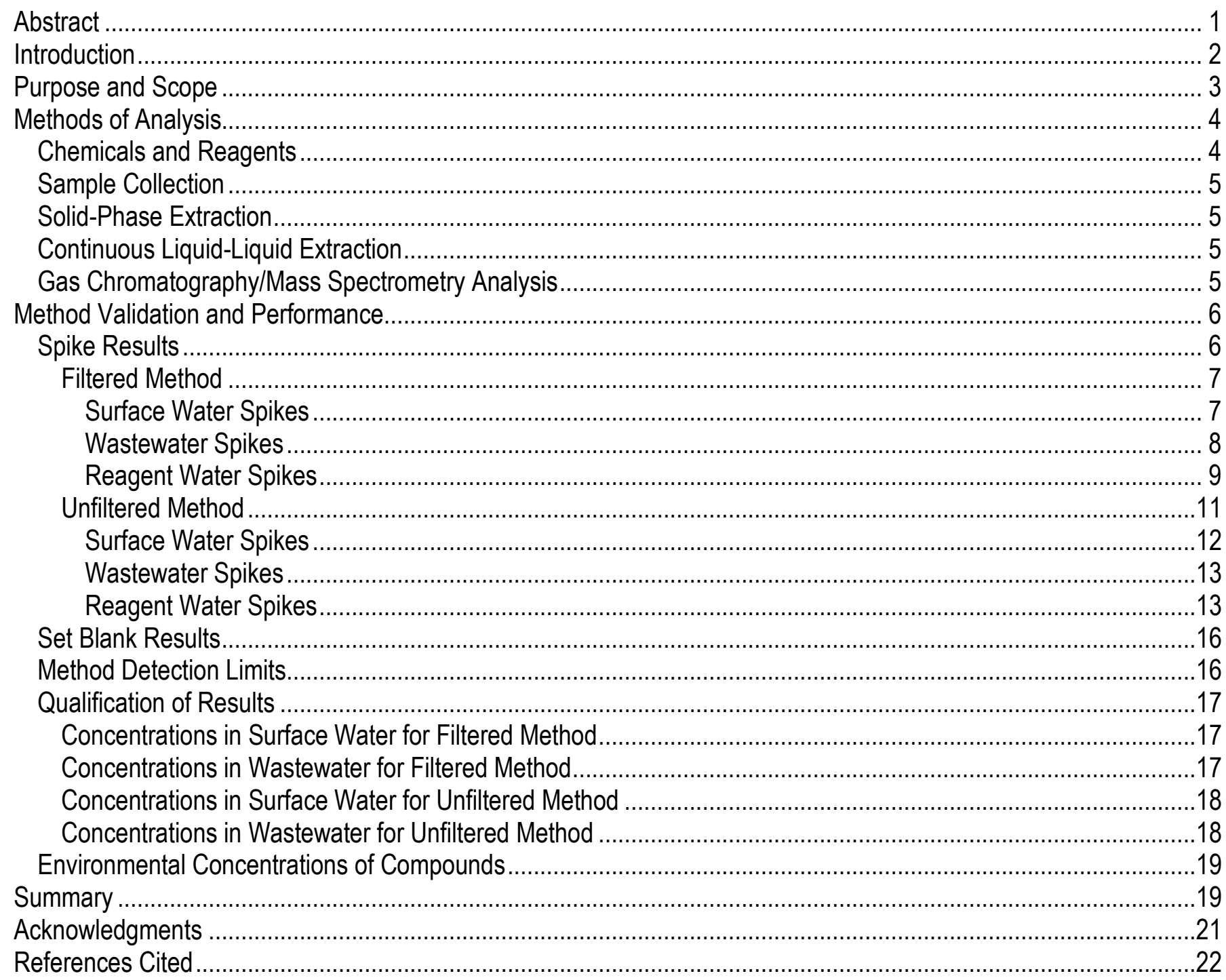




\section{Tables}

Table 1. Compound, possible application, CAS Registry Number, retention time, quantitation ion, confirmation ions, surrogate compounds, internal standard reference compounds, and National Water Inventory System parameter code for filtered- and unfiltered-water analysis.

Table 2. Concentrations used to prepare standard mixtures for spike-fortification mixtures by compound............ 5

Table 3. Filtered water method mean bias and precision of spike data for eight replicates of surface water spiked at indicated low and high fortification levels.

Table 4. Filtered water method mean bias and precision of spike data for eight replicates of wastewater spiked at indicated low and high fortification levels.

Table 5. Filtered water method mean bias and precision of set spike data for reagent water, including 54 set spike samples analyzed during $2010-11$ and 36 set spikes for chiral-d.

Table 6. Filtered water method mean bias and precision of spike data for seven replicates of reagent water spiked at indicated low and high fortification levels

Table 7. Unfiltered water method mean bias and precision of spike data for eight replicates of surface water spiked at indicated low and high fortification levels

Table 8. Unfiltered water method mean bias and precision of spike data for eight replicates of wastewater spiked at indicated low and high fortification levels.

Table 9. Unfiltered water method mean bias and precision of spike data for reagent water, including 34 set spike samples analyzed during $2010-11$, and 27 set spikes for antipyrine and chiral-d. ....

Table 10. Unfiltered water method mean bias and precision of spike data for seven replicates of reagent water spiked at indicated low and high fortification levels.

Table 11. Method detection limits for compounds for filtered water analysis, in micrograms per liter.

Table 12. Method detection limits for compounds for unfiltered water analysis, in micrograms per liter.

Table 13. Concentrations for compounds for filtered method in samples from a stream site below the effluent discharge (site NY1D) and samples of effluent from a wastewater-treatment plant (site NY1E), collected between September 2010 and May 2011.

Table 14. Concentrations for compounds for unfiltered method in five stream samples and samples of effluent from three wastewater-treatment plants, collected in October and November 2011, and December 2009, respectively. 


\section{Conversion Factors}

Inch/Pound to SI

\begin{tabular}{lll}
\hline \multicolumn{1}{c}{ Multiply } & \multicolumn{1}{c}{ By } & \multicolumn{1}{c}{ To obtain } \\
\hline foot (ft) & Length & \\
mile (mi) & 0.3048 & meter $(\mathrm{m})$ \\
\hline & 1.609 & kilometer $(\mathrm{km})$ \\
\hline ounce, fluid (fl. oz) & Volume & \\
gallon (gal) & 0.02957 & liter (L) \\
cubic inch (in $\left.{ }^{3}\right)$ & 3.785 & liter $(\mathrm{L})$ \\
\hline & 0.01639 & liter $(\mathrm{L})$ \\
\hline ounce, avoirdupois (oz) & Mass & \\
\hline
\end{tabular}

Temperature in degrees Celsius $\left({ }^{\circ} \mathrm{C}\right)$ may be converted to degrees Fahrenheit $\left({ }^{\circ} \mathrm{F}\right)$ as follows:

${ }^{\circ} \mathrm{F}=\left(1.8 \times^{\circ} \mathrm{C}\right)+32$

Concentrations of chemical constituents in water are given either in micrograms per liter ( $\mu \mathrm{g} / \mathrm{L})$ or nanograms per liter ( $\mathrm{ng} / \mathrm{L})$.

\section{Abbreviations}

$\begin{array}{ll}{ }^{\circ} \mathrm{C} / \mathrm{min} & \text { degree Celsius per minute } \\ \mu \mathrm{L} & \text { microliter } \\ \mu \mathrm{m} & \text { micrometer } \\ \mathrm{mL} & \text { milliliter } \\ \mathrm{mL} / \mathrm{min} & \text { milliliter per minute } \\ \mathrm{ng} / \mu \mathrm{L} & \text { nanogram per microliter } \\ \mathrm{CAS} & \text { Chemical Abstracts Service } \\ \mathrm{CASRN} & \text { Chemical Abstracts Service registry number } \\ \mathrm{DCM} & \text { dichloromethane } \\ \mathrm{DEE} & \text { diethyl ether } \\ \mathrm{GC} / \mathrm{MS} & \text { gas chromatography/mass spectrometry } \\ \mathrm{MDL} & \text { method detection limit } \\ \mathrm{NWQL} & \text { National Water Quality Laboratory } \\ \text { RSD } & \text { relative standard deviation } \\ \mathrm{SPE} & \text { solid-phase extraction } \\ \text { USGS } & \text { U.S. Geological Survey } \\ \text { WWTP } & \text { wastewater-treatment plant } \\ > & \text { greater than } \\ < & \text { less than } \\ \pm & \text { plus or minus }\end{array}$




\title{
Analysis of Pharmaceutical and Other Organic Wastewater Compounds in Filtered and Unfiltered Water Samples by Gas Chromatography/Mass Spectrometry
}

\author{
By Steven D. Zaugg, Patrick J. Phillips, and Steven G. Smith
}

\begin{abstract}
Research on the effects of exposure of stream biota to complex mixtures of pharmaceuticals and other organic compounds associated with wastewater requires the development of additional analytical capabilities for these compounds in water samples. Two gas chromatography/mass spectrometry (GC/MS) analytical methods used at the U.S. Geological Survey National Water Quality Laboratory (NWQL) to analyze organic compounds associated with wastewater were adapted to include additional pharmaceutical and other organic compounds beginning in 2009. This report includes a description of method performance for 42 additional compounds for the filtered-water method (hereafter referred to as the filtered method) and 46 additional compounds for the unfiltered-water method (hereafter referred to as the unfiltered method). The method performance for the filtered method described in this report has been published for seven of these compounds; however, the addition of several other compounds to the filtered method and the addition of the compounds to the unfiltered method resulted in the need to document method performance for both of the modified methods. Most of these added compounds are pharmaceuticals or pharmaceutical degradates, although two nonpharmaceutical compounds are included in each method. The main pharmaceutical compound classes added to the two modified methods include muscle relaxants, opiates, analgesics, and sedatives. These types of compounds were added to the original filtered and unfiltered methods largely in response to the tentative identification of a wide range of pharmaceutical and other organic compounds in samples collected from wastewatertreatment plants.

Filtered water samples are extracted by vacuum through disposable solid-phase cartridges that contain modified polystyrene-divinylbenzene resin. Unfiltered samples are extracted by using continuous liquid-liquid extraction with dichloromethane. The compounds of interest for filtered and unfiltered sample types were determined by use of the capillary-column gas chromatography/mass spectrometry.

The performance of each method was assessed by using data on recoveries of compounds in fortified surface-water, wastewater, and reagent-water samples. These experiments (referred to as spike experiments) consist of fortifying (or spiking) samples with known amounts of target analytes. Surfacewater-spike experiments were performed by using samples obtained from a stream in Colorado (unfiltered method) and a stream in New York (filtered method). Wastewater spike experiments for both the filtered and unfiltered methods were performed by using a treated wastewater obtained from a single wastewater treatment plant in New York. Surface water and wastewater spike experiments were fortified at both low and high concentrations and termed low- and high-level spikes, respectively. Reagent water spikes were assessed in three ways: (1) set spikes, (2) a low-concentration fortification experiment, and (3) a high-concentration fortification experiment. Set spike samples have been
\end{abstract}


determined since 2009, and consist of analysis of fortified reagent water for target compounds included for each group of 10 to 18 environmental samples analyzed at the NWQL. The low-concentration and high-concentration reagent spike experiments, by contrast, represent a one-time assessment of method performance. For each spike experiment, mean recoveries ranging from 60 to 130 percent indicate low bias, and relative standard deviations (RSDs) less than $(<) 30$ percent indicate low variability.

Of the compounds included in the filtered method, 21 had mean recoveries ranging from 63 to 129 percent for the low-level and high-level surface-water spikes, and had low ( $<15$ percent) RSDs for these spikes. The remaining 21 compounds generally had high bias for the low-level or the high-level spike experiments for surface water [mean recoveries $<58$ percent or greater than $(>) 132$ percent]. For wastewater spikes, 24 of the compounds included in the filtered method had recoveries ranging from 61 to 130 percent for the low-level and high-level spikes. RSDs were $<29$ percent for both of these spike experiments for the 24 compounds. The remaining 18 compounds in the filtered method generally had high recoveries ( $>130$ percent) or variable recoveries (RSDs $>30$ percent) for low-level wastewater spikes, or low recoveries ( $<60$ percent) for high-level wastewater spikes. Of the compounds included in the filtered method, 34 had mean set-spike recoveries between 61 and 126 percent, and RSDs $<30$ percent.

Of the compounds included in the unfiltered method, 17 had mean spike recoveries ranging from 74 to 129 percent and RSDs ranging from 5 to 25 percent for low-level and high-level surface water spikes. The remaining compounds had poor mean recoveries ( $<60$ or $>130$ percent), or high RSDs ( $>29$ percent) for these spikes. For wastewater, 14 of the compounds included in the unfiltered method had mean recoveries ranging from 62 to 127 percent and RSDs $<25$ percent for the low-level and highlevel spikes. Most of the remaining compounds had high mean recoveries for wastewater ( $>130$ percent), or low mean recoveries ( $<20$ percent) or high RSDs ( $>33$ percent) for the low-level wastewater spikes. Of the compounds found in wastewater, 24 had mean set spike recoveries ranging from 64 to 104 percent and RSDs $<30$ percent.

Separate method detection limits (MDLs) were computed for surface water and wastewater for both the filtered and unfiltered methods. Filtered method MDLs ranged from 0.007 to 0.14 microgram per liter $(\mu \mathrm{g} / \mathrm{L})$ for the surface water matrix and from 0.004 to $0.62 \mu \mathrm{g} / \mathrm{L}$ for the wastewater matrix. Unfiltered method MDLs ranged from 0.014 to $0.33 \mu \mathrm{g} / \mathrm{L}$ for the surface water matrix and from 0.008 to $0.36 \mu \mathrm{g} / \mathrm{L}$ for the wastewater matrix.

\section{Introduction}

The effects of low-level exposure of stream biota to complex mixtures of pharmaceuticals and other organic compounds associated with wastewater are poorly understood. A variety of potential adverse effects of pharmaceuticals have been documented at low concentrations, including acute and chronic toxicity (Quinn and others, 2008; Crane and others, 2006; Pomati and others, 2006), accumulation in tissues (Brooks and others, 2003; Paterson and Metcalfe, 2008; Schultz and others, 2011), reproductive effects (Nentwig, 2007), and altered fish behavior (Painter and others, 2009). In addition, high concentrations of pharmaceuticals from discharges by pharmaceutical production facilities have been linked to reduced growth, adverse physiological changes, and lethal effects in fish (Carlsson and others, 2009), masculinization of fish (Sanchez and others, 2011) as well as physiological effects on invertebrates (Gunnarsson and others, 2009). Continued research is needed to identify and quantify pharmaceuticals discharged to aquatic environments, and understand the potential effect of these pharmaceuticals on the health of stream ecosystems. Characterizing the occurrence and effects of pharmaceuticals in the environment will provide information needed to help protect water quality and 
preserve aquatic community health. This research requires the development of additional analytical capabilities for water samples that includes pharmaceuticals and other compounds.

During the last decade, studies documented the occurrence of pharmaceuticals in streams (Ashton and others, 2004; Bruchet and others, 2005; Kim and others, 2007; Kolpin and others, 2002). Wastewater-treatment plants (WWTPs) are a primary source of these compounds to the environment (Clara and others, 2005; Glassmeyer and others, 2005; Vieno and others, 2007; Lin and others, 2008). Facilities involved in the manufacture of pharmaceutical products have been identified as a source of pharmaceutical compounds, as discharges of wastewater from pharmaceutical manufacturing facilities have been observed to result in high concentrations of pharmaceutical compounds being released to the environment (Larsson and others, 2007; Fick and others, 2009; Phillips and others, 2010a). Wastewater from these facilities may be discharged directly (after treatment) to receiving waters or can be discharged to a WWTP for treatment and subsequent discharge to receiving waters.

Previous investigations into the presence of pharmaceuticals in wastewater samples identified several pharmaceuticals as tentatively identified compounds (Phillips and others, 2010). In order to quantitatively assess the occurrence of these compounds in water samples, two gas chromatography/mass spectrometry (GC/MS) analytical methods, developed for analysis of a wide range of organic compounds commonly present in wastewater, were modified to include pharmaceutical and other wastewater associated compounds. The first method is suitable for filtered water samples and uses solid-phase extraction (Zaugg and others, 2002), and the second method is suitable for unfiltered water samples and uses continuous liquid-liquid extraction (Zaugg and others, 2006). Analysis of seven of the pharmaceuticals using the filtered water method began in 2004 and is described along with method-performance data for the same time frame by Phillips and others (2010b). . The addition of several other compounds to this method has resulted in the need to document method performance for additional compounds.

\section{Purpose and Scope}

This report documents a modification of two existing U.S. Geological Survey (USGS) gas chromatography/mass spectrometry (GC/MS) analytical methods-USGS Method Number O-2439-13 described by Zaugg and others (2002) and USGS Method Number O-4439-13 described by Zaugg and others (2006) — to add select pharmaceuticals and other organic compounds. The modified methods include 42 additional compounds for the filtered-water method and 46 additional compounds for the unfiltered-water method.

The method performance for the filtered-water method (referred to as the filtered method) described in this report has been published for seven compounds (Phillips and others, 2010b); the method performance for additional compounds for this method and the existing unfiltered-water method (referred to as the unfiltered method) are documented herein. Details of the methods used to identify these compounds are given in Phillips and others (2010b). This report includes a description of method performance for 42 additional compounds for the filtered method and 46 additional compounds for the unfiltered method. These additional pharmaceuticals include opiates, muscle relaxants, and some of the most frequently prescribed medications in the United States (Pharmacy Times, 2011). Although most of the compounds added to these methods are pharmaceuticals, two non-pharmaceutical compounds (piperonyl butoxide and chloroxylenol) and some pharmaceutical degradates are also included.

A variety of method performance measure data in this report are included in this report. Much of the data used to describe method performance is based on results of experiments ((referred to as spike experiments) consist of fortifying (or spiking) water samples with known amounts of target analytes. Additional performance data include method detection limit determinations for the 42 and 46 analytes 
(listed in table 1) for filtered and unfiltered samples. Results of method performance measures are discussed for the different matrix types (surface water, wastewater, and reagent water) and for the different methods (filtered and unfiltered) for the compounds included in the method. Comparable method performance data are available for seven of the analytes for the filtered method from a study done in 2010 by Phillips and others (2010b); results from this earlier study subsequently are referred to as "the 2010 study" in this report. Select filtered method performance results for the method described in this report are compared to the results of the 2010 study to determine if there are any differences in method performances between the two studies.

Environmental data generated by these two modified methods have been available since 2009, and this method has been used for surface-water, groundwater, wastewater-influent and wastewatereffluent samples. Data for the seven analytes presented in Phillips and others (2010b) have been generated since 2004, and should be comparable to data generated using the unfiltered method described in this report. Concentration data for select surface-water and wastewater samples are included in this report for the filtered and unfiltered methods to illustrate the application of this method to environmental settings.

Table 1. Compound, possible application, CAS Registry Number, retention time, quantitation ion, confirmation ions, surrogate compounds, internal standard reference compounds, and National Water Inventory System parameter code for filtered- and unfiltered-water analysis.

\section{Methods of Analysis}

The following sections describe the methods of analysis used to identify pharmaceutical and organic compounds, including chemicals and reagents used for the analytical methods, sample collection, extraction methods, and the gas chromatography/mass spectrometry analysis.

\section{Chemicals and Reagents}

The pharmaceuticals used to prepare laboratory standards were purchased from Sigma Aldrich and Grace Davidson Discovery Sciences, St. Louis, Missouri, except for metaxalone (Toronto Research Chemicals, Ontario, Canada) and pentoxifylline (Alexis Biochemicals Corporation, San Diego, California.) The reagents used for sample preparation, including dichloromethane (DCM), diethyl ether (DEE), and acetone, were purchased from VWR International (Burdick \& Jackson Brand, Muskegon, Michigan; pesticide grade or better). The reagent water used for analyte fortification and set spike and blank determination was in-house-prepared, deionized water purified through a Solution 2000 system (Solution Consultants, Inc., Jasper, Georgia). The solid-phase extraction (SPE) cartridges were purchased from Waters, Inc. (Milford, Massachusetts; 6-milliliter (mL) barrel packed with 0.5 grams (g) of OASIS-HLB ${ }^{\mathrm{TM}}$ phase, part number 186000115). The internal standard compounds (acenaphthene$d_{10}$, phenanthrene- $d_{10}$, chrysene- $d_{12}$, and perylene- $d_{12}$ ) and surrogate compounds (decafluorobiphenyl, fluoranthene- $d_{10}$, and caffeine- $d_{9}$ ) were purchased from Cambridge Isotope Laboratories (Andover, Mass.).

The preparation of pharmaceutical compound standard mixtures for the analyses described in this report was done at the U.S. Geological Survey National Water Quality Laboratory (NWQL) at different concentrations based on compound-specific instrument responses. Thus, eight multilevel mixtures with individual compound concentrations ranging from 0.02 to $0.16,0.04$ to $0.32,0.10$ to 0.8 , 0.20 to $1.6,0.5$ to $4.0,1.0$ to $8.0,2.5$ to 20 , and 5.0 to 40 nanograms per microliter (ng/ $\mu \mathrm{L}$ ) (table 2) were used for instrument calibration. The $0.02-0.16-\mathrm{ng} / \mu \mathrm{L}$ mixture was used to prepare the lowerconcentration-level validation-spike fortification samples, and the $0.2-1.6-\mathrm{ng} / \mu \mathrm{L}$ concentration-range 
mixture was used to prepare the higher-concentration -level validation-spike fortification samples and the laboratory set spike samples. All other materials and equipment have been described previously for the filtered method (Zaugg and others, 2002) and unfiltered method (Zaugg and others, 2006).

Table 2. Concentrations used to prepare standard mixtures for spike-fortification mixtures by compound.

\section{Sample Collection}

Water samples were collected in 1-Liter (L) amber glass pesticide bottles according to standard USGS sampling procedures for the determination of trace organic compounds (Wilde and others, 2004, with updates through 2009) and shipped at 4 degrees Celsius $\left({ }^{\circ} \mathrm{C}\right)$ to the NWQL. If the samples required filtration, samples were filtered in the field using glass-fiber filters $(0.7$ micrometer nominal pore diameter) as described in the USGS field manual by Wilde and others (2004, with updates through 2009). Upon receipt, samples at the NWQL immediately were treated with the addition of 60 plus or minus $( \pm) 10 \mathrm{~g}$ sodium chloride and stored at $4{ }^{\circ} \mathrm{C}$ for as long as 2 weeks, the appropriate holding time before extraction for the original GC/MS methods. Immediately before the samples were extracted, surrogate compounds were added to monitor method performance.

\section{Solid-Phase Extraction}

Filtered water samples were extracted on a disposable SPE cartridge packed with $0.5 \mathrm{~g}$ OASIS HLB $^{\text {TM }}$ adsorbent at a flow rate of about 40 millliters per minute $(\mathrm{mL} / \mathrm{min})$. The SPE cartridges were dried with nitrogen gas. The sample bottles were rinsed thoroughly with $17 \mathrm{~mL}$ of a mixture of DCM and DEE (a ratio of 4 to 1, volume per volume). The DCM-DEE rinsate also was used to elute sorbed compounds from the corresponding SPE cartridges. The resulting extract was reduced under nitrogen gas to a final volume of 400 microliters $(\mu \mathrm{L})$. Isotopically labeled internal standard compounds were added to the extract $(20 \mu \mathrm{L}$ of internal standard solution added at a concentration of $100 \mathrm{ng} / \mu \mathrm{L})$. Method compounds were determined by capillary-column GC/MS in the full-scan, electron impact mode as described by Zaugg and others (2002).

\section{Continuous Liquid-Liquid Extraction}

Unfiltered samples were transferred to a continuous liquid-liquid extraction vessel equipped with a porous glass frit to disperse microdroplets of DCM (for improved extraction efficiency) to extract at ambient $\mathrm{pH}$ for 3 hours, and then at $\mathrm{pH} 2$ (adjusted by the addition of $5 \mathrm{~mL} \mathrm{1-Normal} \mathrm{hydrochloric} \mathrm{acid}$ for 3 hours. The DCM extract was evaporated by using a gentle stream of nitrogen gas and reduced to a final volume of $400 \mu \mathrm{L}$. Isotopically labeled internal standard compounds were added to the extract ( $20 \mu \mathrm{L}$ of internal standard solution added at a concentration of $100 \mathrm{ng} / \mu \mathrm{L}$ ). Method compounds were determined by capillary-column GC/MS in the full-scan, electron impact mode as described by Zaugg and others (2006).

\section{Gas Chromatography/Mass Spectrometry Analysis}

All sample extracts (from filtered or unfiltered water) were analyzed on an Agilent Technologies, Model 6890 gas chromatograph and Model 5975 mass spectrometer. Separations were done using a 30 meter $(\mathrm{m})$ by 0.25 millimeter $(\mathrm{mm})$ inside diameter fused-silica capillary column coated with a $0.50-\mu \mathrm{m}$ bonded film of 5-percent phenylmethyl silicone (Agilent Technologies). A 2- $\mu \mathrm{L}$ volume of sample extract was injected in splitless mode ( $0.7 \mathrm{~min}$ [minute]) at an injection port temperature of $290{ }^{\circ} \mathrm{C}$. The oven temperature was programmed as follows: initial temperature of $40^{\circ} \mathrm{C}$, then ramped at 
4 degree celsius per minute $\left({ }^{\circ} \mathrm{C} / \mathrm{min}\right)$ to $100{ }^{\circ} \mathrm{C}$, and then $8{ }^{\circ} \mathrm{C} / \mathrm{min}$ to $220{ }^{\circ} \mathrm{C}, 15^{\circ} \mathrm{C} / \mathrm{min}$ to $270{ }^{\circ} \mathrm{C}$, and $9{ }^{\circ} \mathrm{C} / \mathrm{min}$ to $350^{\circ} \mathrm{C}$ with a hold time of 2 minutes. The electronic pressure control was set to deliver a constant flow of helium carrier gas of $\mathrm{ml} / \mathrm{min}$. The mass spectrometer was set as follows: $150{ }^{\circ} \mathrm{C}$ analyzer, $230{ }^{\circ} \mathrm{C}$ source, $290^{\circ} \mathrm{C}$ interface, and electron ionization mode at 70 electron volts. Full-scan data was collected from 50 to 550 atomic mass units. Method compounds, possible uses, Chemical Abstract Services Registry Number, retention time, quantitation ions, and confirmation ions are listed in table 1, which also includes the same information for surrogates and internal standards, along with National Water Information System parameter codes for each analyte. Compounds that initially were considered for inclusion in the method, but were not included because of poor high, low, or inconsistent performance in set spikes are listed in appendix 1.

Positive identification of a compound required elution within the expected retention time window of \pm 0.1 minutes of the expected retention time. The base-peak ion was used for quantitation and two qualifier ions were used for confirmation. In addition, the sample spectra and ion abundance ratios were required to match within \pm 20 percent of the reference standard compounds. After qualitative criteria were met, compound concentrations were calculated for samples using eight-point calibration curves (see table 2 for specific calibration-concentration ranges by compound) and internal standard quantitation.

\section{Method Validation and Performance}

Method validation and performance are assessed in the sections below using results of low-level and high-level fortification spike data and set blank data. The results of the spike experiments are discussed separately for the filtered and unfiltered methods. Set blank data pertain to both methods and therefore are discussed in a single section following the spike results. A holding time study was not performed for the target analysis as part of this study. The average holding time (time between sample collection date and extraction date) for the filtered method samples analyzed by the NWQL in 2010 was 7.5 days, with the holding time ranging from 2 to 27 days. The average holding time for the unfiltered method samples analyzed by the NWQL in 2010 was 8.8 days, with the holding time ranging from 4 to 18 days.

\section{Spike Results}

The performance of both the filtered and unfiltered methods was tested using spike data from three different types of water: (1) surface water, (2) treated wastewater effluent, and (3) reagent water. Because samples from studies using this method mostly were from surface water and WWTPs, method performance generally was assessed using results of spiking experiments with surface water and treated wastewater effluent (hereafter referred to as "wastewater"). Surface water samples were collected from Bear Creek $2.7 \mathrm{~km}$ (kilometers) downstream from Morrison, Colorado. Wastewater samples were collected at the final effluent point from a trickling filter WWTP in southeastern New York [this WWTP is described in Phillips and others (2010b), and is referred to as site NY1E]. Reagent water spikes were assessed in three ways: (1) set spikes, (2) a low-concentration fortification experiment, and (3) a highconcentration fortification experiment.

Each of the three matrices included in the spiking experiments (surface water, wastewater, and reagent water) were fortified in eight replicates using a low $(0.04-0.64 \mu \mathrm{g} / \mathrm{L})$ and a high $(0.4-6.4 \mu \mathrm{g} / \mathrm{L})$ concentration-range mixture, hereafter referred to as "low-level spikes" and "high-level spikes." The three sample matrices were extracted and analyzed in unfortified samples to determine concentrations of analytes present in these matrices. Recoveries were corrected for concentrations present in unfortified 
samples by subtracting the mean concentrations of these unfortified samples from the reported concentrations in the fortified samples. Method performance also was assessed using set spike data. The set spike samples consist of spiking a known amount of the target analytes into reagent water samples. At least one fortified laboratory spike is analyzed with each set of as many as 10 and 18 environmental samples for the filtered water and unfiltered water methods, respectively. The set spike results indicate the performance of the method during an extended period in the absence of sample matrices, which variably can alter recoveries. The concentration of compounds in the set spike is comparable to the range used in the high-level fortification experiments for surface water, wastewater, and reagent water.

Method performance for the spike data largely is based on recovery of analytes, assessed using median recovery percentage, and variability in recovery, assessed using relative standard deviation (RSD), expressed as a percent. For each spike experiment, median recoveries that range from 60 to 130 percent indicate low bias, and relative standard deviations less than $(<) 30$ percent indicate low variability; these criteria are similar to those used in Phillips and others (2010b). These criteria are used to distinguish analytes that have low bias, low, low variability, or both, from analytes high bias, high variability, or both. These criteria are used to help the reader understand the variability in method performance for different types of matrices.

\section{Filtered Method}

Recoveries for surface water and wastewater spike experiments indicated low bias, low variability or both for many compounds included in the filtered method. Results of spike experiments for the filtered method surface water spikes are shown in table 3, and results of spike experiments for the filtered method wastewater spikes are shown in table 4. Results of set spikes for the filtered method are provided in table 5, and results of spike experiments for low-level and high-level reagent spikes are shown in table 6. These results are compared with results of surface water, wastewater, and reagent water spike experiments for seven of these compounds described in Phillips and others (2010b) to illustrate similarities and differences of method performance between the two studies.

Table 3. Filtered water method mean bias and precision of spike data for eight replicates of surface water spiked at indicated low and high fortification levels.

Table 4. Filtered water method mean bias and precision of spike data for eight replicates of wastewater spiked at indicated low and high fortification levels.

Table 5. Filtered water method mean bias and precision of set spike data for reagent water, including 54 set spike samples analyzed during 2010-11 and 36 set spikes for chiral-d.

Table 6. Filtered water method mean bias and precision of spike data for seven replicates of reagent water spiked at indicated low and high fortification levels.

\section{Surface Water Spikes}

Of the compounds included in the filtered method, 21 had low bias and low variability for the low-level and high-level surface water spikes (table 3). Mean recoveries for these 21 compounds ranged from 78 to 129 percent for the low-level surface-water spikes and 63 to 91 percent for the high-level surface water spikes. RSDs for these 21 compounds ranged from 2 to 14 percent for both the low-level and high-level surface water spikes. These 21 compounds are denoted in table 3 as "Compounds with low bias and low variability for low-level and high-level spikes." 
Some compounds (butalbital, carisoprodol, chirald, methadone, methylphenidate, oxycodone, pentobarbital, temazepam, and tramadol) had high bias for the filtered method for the low-level surface water spikes (table 3). Mean recoveries for these nine compounds generally ranged from 133 to 193 percent for the low-level surface water spikes; mean recovery for one of these compounds (methylphenidate) was low (39 percent). Mean recoveries for these nine compounds for the high-level surface-water spikes ranged from 64 to 92 percent. RSDs for these nine compounds for both the lowlevel and high-level spikes ranged from 2 to 17 percent. Several (butalbital, carisoprodol, chiral-d, methadone, oxycodone, pentobarbital, and temazepam) of these nine compounds had low-level recoveries ranging from 133-142 percent, and so were slightly higher than the 130 percent mean recovery used to distinguish low bias from high bias. Reported concentrations for these nine compounds may be biased high at low concentrations, but these results indicate that they have low bias for high concentrations and low variability for both high and low concentrations. These compounds are denoted in table 3 as "Compounds with high bias for low-level spikes."

A few compounds (methocarbamol, oxacarbazepine, and propofol) had low mean recoveries (28-45 percent) for the high-level surface-water spikes for the filtered method (table 3 ). Of these compounds, two (methocarbamol and propofol) also had high RSDs [greater than ( $>$ )39 percent] for the high-level surface-water spikes. By contrast, the low-level surface-water spikes for these three compounds had mean recoveries ranging from 69 to 99 percent, and RSDs ranging from 6-18 percent. These compounds are denoted in table 3 as "Compounds with high bias, high variability or both for high-level spikes."

The remaining nine compounds (chlorpheniramine, citalopram, codeine, dihydrocodeine, diphenhydramine, hydrocodone, iminostilbene, meperidine, and phenidimetrazine) had recoveries ranging from 19 to 57 percent for both low-level and high-level surface-water spikes. RSDs for these compounds were $<30$ percent for both these spikes. These compounds are denoted in table 3 as "Compounds with high bias for low-level and high-level spikes."

Comparison of the results of this study with surface-water spike data from Phillips and others (2010b) for the seven compounds (butalbital, carisoprodol, diazepam, metaxalone, methadone, oxycodone, phendimetrazine) with available data indicates that the 2010 study results generally are more similar to the high-level surface-water spike results than the low-level surface-water spike results of the current (2013) study. (Throughout the remainder of this report, the 'current study' results refer to the results presented in this report). With the exception of phendimetrazine, the mean high-level spike recoveries for these compounds range from 66 to 89 percent, which is similar to the general range for the mean recoveries in the surface-water spike results for the 2010 study (57-99 percent). The exceptions to these generalizations are the low recovery (47 percent) for phendimetrazine for the highlevel spike in the current study and the low recovery (32 percent) for methadone for the 2010 study. By contrast, the mean low-level surface-water spike recoveries for the current study (115-142 percent) generally were higher than the 2010 study results. The only exception was the low mean recovery ( 24 percent) for phendimetrazine for the low-level spike in the current study. In general, RSDs were low ( $<25$ percent) for the low-level and high-level spikes and the 2010 study spikes; the only exception is the high RSDs (36 and 48 percent) for oxycodone and phendimetrazine, respectively, for the 2010 surface-water spikes.

\section{Wastewater Spikes}

Of the compounds included in the filtered method, 24 had mean recoveries ranging from 61 to 130 percent and RSDs that ranged from 1.3 to 28 percent for the low and high-level wastewater spikes 
(table 4). These 24 compounds are denoted in table 4 as "Compounds with low bias and low variability for low-level and high-level spikes."

Some compounds (phenobarbital, temazepam, and verapamil) had high bias or high variability for the low-level wastewater spikes (table 4). Mean recoveries for two of these three compounds (temazepam and verapamil) were 137 and 155 percent, respectively, but the RSDs for these two compounds were low ( $<8$ percent). Although the mean recovery for phenobarbital was 88 percent for the low-level wastewater spikes, the variability for this compound was high (RSD of 33 percent). Mean recoveries for the high-level wastewater spikes ranged from 65 to 75 percent and RSDs for the highlevel wastewater spikes ranged from 3.9 to 23 percent for these compounds. These three compounds are denoted in table 4 as "Compounds with high bias, high variability, or both for low-level spikes."

Mean recoveries ranged between 26 and 58 percent for the high-level wastewater spikes for the filtered method (table 4) for 11 compounds (chlorpheniramine, citalopram, codeine, dihydrocodeine, diphenhydramine, hydrocodone, iminostilbene, meperidine, methadone, oxcarbazepine, and propofol). By contrast, mean recoveries for these 11 compounds for the low-level wastewater spikes ranged from 66 to 102 percent. RSDs for low-level and high-level wastewater spikes were low for these compounds (3-24 percent). Most of these 11 compounds (chlorpheniramine, citalopram, codeine, dihydrocodeine, diphenhydramine, hydrocodone, meperidine, and methadone) had high-level mean recoveries ranging from 55 to 58 percent, and so had slightly lower recoveries than the 60-percent mean recovery used to distinguish low bias from high bias. These 11 compounds are denoted in table 4 as "Compounds with high bias for high-level spikes."

The remaining four compounds (fluconazole, methocarbamol, phendimetrazine, and primidone) had high bias for both the low-level and high-level wastewater spikes. Mean recoveries for these compounds ranged from 0 to 54 percent for the low-level wastewater spikes and 32 to 57 percent for the high-level wastewater spikes (table 4). RSDs also were high (>32 percent) for both of these spikes for all four of these compounds except phendimetrazine. Phendimetrazine had mean recoveries ranging from 54 to 56 percent and RSDs $<12$ percent for both the low-level and high-level spikes. These compounds are denoted in table 4 as "Compounds with high bias, high variability or both for low-level and high-level spikes."

Comparison of the results of this study for seven compounds (butalbital, carisoprodol, diazepam, metaxalone, methadone, oxycodone, and phendimetrazine) with available data from the 2010 study (Phillips and others, 2010b) indicates similar results for the wastewater spikes. The range in recoveries for the seven compounds for wastewater spikes in the current study generally was from 58 to 130 percent, and RSDs ranged from 1 to 15 percent. Recoveries for wastewater spikes for the 2010 study for these compounds generally ranged from 59 to 120 percent, and all RSDs ranged from 3 to 31 percent. In both studies, phendimetrazine recoveries were low compared to the recoveries for the other six compounds, ranging from 54 to 56 percent in the current study to 66 to 70 percent in the 2010 study.

\section{Reagent Water Spikes}

Reagent spike data for the filtered method are available for reagent set spikes (table 5), and (2) the low-level and high-level reagent spike experiments (table 6). Reagent spike data are useful for indicating method performance in the absence of sample matrices, which variably can alter recoveries. Throughout this section, the reagent set spikes are referred to as set spikes, whereas the low-level and high-level reagent spike experiments are referred to as low-level and high-level spikes. Set spike results are the primary source of information for method performance of reagent water due to the extended period (between 2010 and 2011) and large number of set spike analyses (generally 54) available for 
analytes. The low-level and high-level spike experiments are a secondary source of information on reagent spike performance.

Of the compounds included in the filtered method, 34 had mean set spike recoveries ranging from 61 to 126 percent, and RSDs ranging from 7 to 28 percent (table 5). These compounds are denoted in table 5 as "Compounds with low bias and low variability for set spikes." The remaining eight compounds had either low mean recoveries or high RSDs for the set-spikes for the filtered method. Four of these compounds (chlorpheniramine, dihydrocodeine, methocarbamol, and primidone) had mean setspike recoveries ranging from 34 to 58 percent; two of these four compounds (chlorpherniramine and primidone) had mean set spike recoveries of 58 and 53 percent, respectively, suggesting a small negative bias for the set-spike results for these two compounds in comparison to the other compounds with low mean set spike recoveries. RSDs for these four compounds ranged from 13 to 28 percent. The remaining four compounds (fluconazole, meprobamate, oxcarbazepine, and propofol) had recoveries ranging from 76 to 105 percent, but had RSDs ranging from 35 to 53 percent. These eight compounds are denoted in table 5 as "Compounds with high bias, high variability, or both for set spikes."

Of the compounds in the filtered method, 14 had mean recoveries between 71 and 129 percent and RSDs between 3 and 23 percent for the low-level and high-level spikes. These compounds are denoted in table 6 as "Compounds with low bias and low variability for low-level and high-level spikes."

A few compounds (chirald, fluconazole, lidocaine, temazepam, and tramadol) generally had low mean recoveries and high RSDs for the low-level spikes for the filtered method. Four (fluconazole, lidocaine, temazepam, and tramadol) of these five compounds had mean low recoveries ranging from 0 to 59 percent. The mean low-level recovery for temazepam was 59 percent, indicating that the negative bias for this compound was smaller than the other three compounds for the low-level spike. RSDs for three compounds (chirald, fluconazole, and lidocaine) were high (37-62 percent). Mean high-level spike recovery for these five compounds ranged from 61 to 81 percent, and RSDs for these spikes ranged from 6 to 17 percent, suggesting low bias and low variability for the high-level spikes. These five compounds are denoted in table 6 as "Compounds with high bias, high variability or both for low-level spikes."

Five compounds (antipyrine, celecoxib, oxacarbazepine, primidone, and propofol) had low mean recoveries (18-56 percent) for the high-level spikes for the filtered method. RSDs for two of these compounds (antipyrine and propofol) were high (35 and 43 percent) for the high-level spikes, but were low $(<16$ percent) for the remaining three compounds in this group. The mean high-level recovery for primidone was 56 percent, indicating that the negative bias for this compound was smaller than the other four compounds for the high-level spike. By contrast, mean low-level spikes for these five compounds ranged from 61 to 88 percent, and RSDs for these spikes ranged from 7 to 24 percent. These compounds are denoted in table 6 as "Compounds with high bias, high variability, or both for high-level spikes."

The remaining 18 compounds generally had mean recoveries for the filtered method for both the low-level and high-level spikes between 0 and 47 percent (table 6). The only exception to this generalization is for chloroxylenol, which had a mean recovery of 82 percent for the low-level spike and 71 percent for the high-level spike. Chloroxylenol had high RSDs for the low-level and high-level spikes (42 and 33 percent, respectively). These compounds are denoted in table 6 as "Compounds with high bias, high variability, or both for low-level and high-level spikes."

The filtered method had more compounds with low variability and low bias for the set spikes compared to the low-level and high-level spikes. Thirteen compounds (2-ethyl-2-phenylmalonamide, butalbital, carbamazepine, carisoprodol, diazepam, efavirenz, griseofulvin, metaxalone, pentobarbital, 
pentoxifylline, phenobarbital, phenytoin, and piperonyl butoxide) had low bias and low variability for the set spikes, and the low-level and high-level spikes.

The remaining 21 compounds (antipyrine, celecoxib, chirald, chloroxylenol, citalopram, codeine, diltiazem, diphenhydramine, hydrocodone, iminostilbene, lidocaine, meperidine, methadone, methylphenidate, oxycodone, phendimetrizine, temazepam, ticlopidine, tramadol, venlafaxine, verapamil) with low bias and low variability for set spikes had high bias, high variability or both for one or both of the low-level and high-level spikes. Thus, less than one-half of the compounds with low bias and low variability for the set spikes had low bias and low variability for the low-level and high-level spikes. The eight compounds (chlorpheniramine, dihydrocodeine, fluconazole, meprobamate, methocarbamol, oxacarbazepine, primidone, and propofol) with high bias, high variability or both for set spikes generally had high bias, high variability, or both for one or both of the low-level and highlevel spikes. The only exception to this is meprobamate, which had low bias, low variability or both for the low-level and high-level spikes.

The cause of the relatively low recoveries for the reagent low-level and high-level spike experiments compared to the reagent set spike recoveries is not clear. One possible explanation for the low recoveries in the reagent-spike validation samples is that there were a greater number of active (sorptive) sites in the GC inlet and column during analyses of the validation samples compared with the GC conditions during analyses of the set spike samples. Many of the analytes have functional groups that are subject to interactions with active sites that can (positively or negatively) affect quantitative performance. Matrices containing co-extracted material can cause both positive and negative bias in recoveries when compared to reagent matrices. The effect can be highly dependent on the analyte and its concentration, and the nature of the co-extracted material. It is suspected that a matrix associated with environmental samples competes with analytes for these active sites, and can produce a beneficial (or negative) effect on analyte performance, as described by Erney and others (1993). Set spikes always are run in conjunction with environmental samples, so the GC inlet can become conditioned (deactivated) with environmental samples that are analyzed before the set spike sample in subsequent sets. Because fewer analyses were performed for the reagent low- and high-level spike experiments $(7$ each) compared to the number of set spike analyses (54), the lower reagent experiment recoveries might be due to anomalous conditions during this experiment. Overall, the large number of samples and longer time period of the set spike results are considered more representative of method performance in reagent water than the low- and high-level spike validation experiments.

The filtered set spike results in this study are similar to the set spike results reported in Phillips and others (2010b). The 2010 study included filtered set spike results for seven compounds (butalbital, carisoprodol, diazepam, metaxalone, methadone, oxycodone, and phendimetrazine) from 2 different years. Mean set spike recoveries for these compounds ranged from 71 to 103 percent and RSDs ranged from 8 to 28 percent in the present study. Mean set spike recoveries for these compounds ranged from 66 to 140 percent and RSDs ranged from 17 to 46 percent for the 2010 study.

\section{Unfiltered Method}

Recoveries for surface water and wastewater spike experiments indicated good method performance for many of the compounds included in the unfiltered method. Results of spike experiments for the unfiltered method for surface-water spikes are shown in table 7. Results of spike experiments for the unfiltered method for wastewater spikes are shown in table 8. Results of set spikes for the unfiltered method are presented in table 9, and results for reagent low-level and high-level spike experiments are shown for the unfiltered method in table 10. 
Table 7. Unfiltered water method mean bias and precision of spike data for eight replicates of surface water spiked at indicated low and high fortification levels.

Table 8. Unfiltered water method mean bias and precision of spike data for eight replicates of wastewater spiked at indicated low and high fortification levels.

Table 9. Unfiltered water method mean bias and precision of spike data for reagent water, including 34 set spike samples analyzed during 2010-11, and 27 set spikes for antipyrine and chiral-d.

Table 10. Unfiltered water method mean bias and precision of spike data for seven replicates of reagent water spiked at indicated low and high fortification levels.

\section{Surface Water Spikes}

Of the 46 compounds included in the unfiltered method, 17 had low bias and low variability for the low-level and high-level surface water spikes (table 7). Median recoveries for these 17 compounds ranged from 79 to 129 percent for the low-level surface water spikes and 74 to 110 percent for the highlevel surface water spikes. RSDs for these 17 compounds ranged from 5 to 25 percent for both the lowlevel and high-level surface water spikes. These 17 compounds are denoted in table 7 as "Compounds with low bias and low variability for low-level and high-level spikes."

Of the compounds included in the unfiltered method, 22 had high bias or high variability for the low-level surface-water spikes (table 7). All but four of these compounds had high mean low-level spike recoveries ( $>132$ percent). Some compounds (celocoxib and methylphenidate) had low ( $<44$ percent) mean low-level spike recoveries, and two compounds (dihydrocodeine and diphenhydramine) had mean recoveries of 110 and 105 percent, respectively. Mean recoveries for these 22 compounds for the highlevel surface-water spikes ranged from 62 to 123 percent. RSDs for these compounds for the low-level and high-level spikes generally ranged from 4 to 27 percent; the only exception is the RSD for low-level surface water spikes of dihydrocodeine and diphenhydramine (30 and 64 percent, respectively). Some compounds (chlorpheniramine, codeine, methadone, norpropoxyphene, oxycodone, pentoxifylline, piperonyl butoxide, temazepam) had slightly elevated recoveries for the low-level spikes (133137 percent), suggesting that the positive bias for these compounds is slight. These 22 compounds are denoted in table 7 as "Compounds with high bias or high variability for low-level spikes."

Some compounds (2-ethyl-2-pehnylmalonamide and venlafaxine) had low mean recoveries (48 and 47 percent, respectively) for the unfiltered high-level surface-water spikes. The mean recovery for the low-level surface-water spike for these two compounds was 86 and 61 percent, respectively. RSDs for the low-level and high-level spikes for these compounds ranged from 9 to 23 percent. These two compounds are denoted in table 7 as "Compounds with high bias for high-level spikes."

Of the compounds included in the method, five compounds (diltiazem, methocarbamol, oxacarbazapine, primidone, and verapamil) had high bias for both the unfiltered low-level and highlevel surface-water spikes (table 7). Some compounds (diltiazem, verapamil, and primidone) had low mean recoveries ( $0-50$ percent) for the low-level surface water spikes, and two compounds (methocarbamol and oxacarbazepine) had high mean recoveries (152 and 190 percent, respectively) for these spikes. Some of these compounds (methocarbamol, oxacarbazepine, and primidone) had low mean recoveries (26-59 percent) for the unfiltered high-level spikes, and the remaining two compounds (diltiazem and verapamil) had high mean recoveries ( $>153$ percent) for the high-level spikes. These compounds are denoted in table 7 as "Compounds with high bias for low-level and high-level spikes." 


\section{Wastewater Spikes}

Of the compounds included in the unfiltered method, 14 had mean spike recoveries that ranged from 62 to 127 percent for the low-level and high-level wastewater spikes (table 8). RSDs for these 14 compounds for the low-level and high-level spikes ranged from 6 to 24 percent. These compounds are denoted in table 8 as "Compounds with low bias and low variability for low-level and high-level spikes."

Many (20) of the remaining compounds had high bias or high variability for the low-level wastewater spikes for the unfiltered method (table 8). A few of these compounds (ibuprofen and oxycodone) had low mean recoveries ( $<20$ percent), whereas 15 of these compounds (antipyrine, carisoprodol, chirald, chlorpheniramine, diazepam, diltiazem, efavirenz, griseofulvin, methadone, norpropoxyphene, pentobarbital, pentoxifylline, phenytoin, piperonyl butoxide, and ticlopidine) had high mean recoveries for the low-level wastewater spikes (133-197 percent). Of the 15 compounds with high mean recoveries three (phenytoin, piperonyl butoxide, and ticlopidine) had low mean recoveries relative to the remaining compounds (ranging from 133 to 139 percent), indicating less positive bias for these compounds compared to the remaining 12 compounds. In general, RSDs for the compounds in this group were low (7-20 percent); however, three compounds (diphenhydramine, iminostilbene, and propofol) had high RSDs (34-37 percent), but had mean recoveries between 87 and 119 percent. Mean recoveries for the high-level wastewater spikes for all these compounds ranged from 61 to 124 percent, and RSDs ranged from 6 to 17 percent. These compounds are denoted in table 8 as "Compounds with high bias or high variability for low-level spikes."

A few compounds (codeine, hydrocodone, methylphenidate, and oxacarbazapine) had high bias for the high-level wastewater spikes for the unfiltered method (table 8). Mean recoveries for these four compounds for the high-level wastewater spikes ranged from 20 to 58 percent. The recovery for codeine (58 percent) was higher than the other three compounds, indicating that the bias for high-level spikes was lower for this compound compared to the other three compounds. Median recoveries for these four compounds ranged from 76 to 116 percent for the low-level wastewater spikes. RSDs for both the lowlevel and high-level spikes ranged from 3 to 19 percent for all four compounds, indicating low variability. These compounds are denoted in table 8 as "Compounds with high bias for high-level spikes."

The remaining 8 compounds (2-ethyl-2-phenylmalonamide, celecoxib, dihydrocodeine, methocarbamol, primidone, temazepam, venlafaxine, and verapamil) had high bias or high variability for the low-level wastewater spikes and high bias for the high-level wastewater spikes for the unfiltered method. Five of these compounds (2-ethyl-2-phenylmalonamide, celecoxib, dihydrocodeine, primidone, and venlafaxine) had low mean recoveries for the low-level spikes (between 0 and 49 percent), and two other compounds (methocarbamol and verapamil) had high mean recoveries ( $>170$ percent). In general, these compounds had low mean recoveries for the high-level spikes (31-53 percent). The only exception was verapamil, which had a high mean recovery (156 percent). RSDs for the low-level and high-level spikes for these eight compounds generally were $<22$ percent. The only exception was temazepam, which had a high RSD (71 percent) for the low-level wastewater spike. These compounds are denoted in table 8 as "Compounds with high bias and (or) high variability for low-level and highlevel spikes."

\section{Reagent Water Spikes}

Reagent spike data for the unfiltered method are available for reagent set spikes, and the lowlevel and high-level spike experiments. Throughout this section, the low-level and high-level reagent spike experiments are referred to as low-level and high-level spikes, whereas the reagent set spikes are 
referred to as set spikes. Set spike results are the primary source of information on method performance due to the extended period (between 2010 and 2011) and large number of set spike analyses (generally 34) available for analytes. The low-level and high-level spike results are a secondary source of information on reagent spike performance.

Of the compounds included in the unfiltered method, 24 had mean set spike recoveries ranging from 64 to 104 percent, and RSDs ranging from 8 to 29 percent (table 9). These compounds are denoted in table 9 as "compounds with low bias and low variability for set spikes."

The remaining 22 compounds included in the unfiltered method had low mean recoveries, high RSDs, or both for set spikes. Less than half (10) of these compounds (2-ethyl-2-phenylmalonamide, codeine, dihydrocodeine, hydrocodone, methocarbamol, norpropoxyphene, oxacarbazepine, oxycodone, primidone, and venlafaxine) had low mean set spike recoveries (26-58 percent). A few of these compounds (codeine, methocarbamol, and venlafaxine) had mean set spike recoveries ranging from 55 to 58 percent, indicating that the negative bias for these compounds is not as strong as for the remaining 19 compounds. Most of these compounds (amitriptyline, carbamazepine, carisoprodol, celecoxib, codiene, dihydrocodeine, diphenhydramine, fluconazole, ibuprofen, metaxalone, phenytoin, temazepam, tramadol, verapamil) had high set spike RSDs (34-57 percent). Only two of these compounds (celecoxib and diphenhydramine) had lower RSDs (both 34 percent) compared to the other 12 compounds with high set spike RSDs, indicating less variability for these two compounds. These 22 compounds are denoted in table 9 as "Compounds with high bias, high variability, or both for set spikes."

Only six of the compounds (carbamazepine, chloroxylenol, griseofulvin, iminostilbene, phenobarbital, and phenytoin) included in the unfiltered method had low bias and variability for lowlevel and high-level spike experiments (table 10). Mean recoveries for these compounds ranged from 66 to 130 percent for both the low-level and high-level spikes, and RSDs ranged from 5 to 29 percent for both spike experiments. These six compounds are denoted in table 10 as "Compounds with low bias and low variability for low-level and high-level spikes."

Of the compounds, 10 compounds had either high or low mean recoveries for the low-level spikes for the unfiltered method (table 10). Most of these 10 compounds (butalbital, carisoprodol, dextromethorphan, diazepam, efavirenz, methadone, pentobarbital, piperonyl butoxide, and ticlopidine) had high mean low-level spike recoveries (133-160 percent), whereas the remaining compound (fluconazole) had a low mean low-level spike recovery (48 percent). Mean recoveries for the high-level spikes for these compounds ranged from 64 to 119 percent for these compounds. RSDs for the low-level spikes for these 10 compounds generally were low (7-12 percent); the one exception to this generalization is fluconazole, which had an RSD of 44 percent for the low-level spike. These 10 compounds are denoted in table 10 as "Compounds with high bias, high variability, or both for lowlevel spikes."

Of the compounds included in the method, 16 compounds had low recoveries, high RSDs or both for the high-level spikes for the unfiltered method (table 10). Although mean high-level spike recoveries for most of these compounds ranged from 61 to 99 percent, three of these compounds (celecoxib, ibuprofen, and oxacarbazapine) had low RSDs for the high-level spikes (24-48 percent). All but 1 of these 16 compounds had RSDs between 31 and 45 percent for the high-level spikes; the only exception was oxacarbazapine, which had an RSD of 4 percent. Most of these compounds (celecoxib, diphenhydramine, ibuprofen, meperidine, meprobamate, metaxalone, pentoxifylline, temazepam) had low RSDs (ranging from 31-34 percent) for the high-level set spikes relative to the other compounds in this group, indicating that variability of these eight compounds was not as great as for the remaining compounds. Mean recoveries for the low-level spikes ranged from 75 to 128 percent for these 
compounds, and RSDs were $<28$ percent for the low-level spikes. These 16 compounds are denoted in table 10 as "Compounds with high Bias, high variability, or both for high-level Spikes."

Of the compounds in the method, 14 had high bias and (or) high variability for both the lowlevel and high-level spikes for the unfiltered method (table 10). Some of these compounds (2-ethyl-2phenylmalonamide, methocarbamol, norpropoxyphene, primidone, propofol, and venlafaxine) had low mean recoveries (0-54 percent) for the low-level spikes, whereas seven of these compounds (amitriptyline, chirald, diltiazem, hydrocodone, oxycodone, tramadol, and verapamil) had high mean recoveries (132-188 percent) for the low-level spikes. RSDs for the fourteen compounds in this group generally were low (7-25 percent) for the low-level spikes. Only 1 of the 14 compounds (dihydrocodeine) had a high RSD (32 percent). Most of these 14 compounds (2-ethyl-2phenylmalonamide, hydrocodone, methocarbamol, norpropoxyphene, oxycodone, primidone, propofol, and venlafaxine) had low mean recoveries for the high-level spikes (28-49 percent). RSDs for all but three (2-ethyl-2-phenylmalonamide, methocarbamol, and primidone) of these compounds were $>30$ percent for the high-level spikes. These 14 compounds are denoted in table 10 as "Compounds with high bias, high variability, or both for low-level and high-level Spikes.",

The unfiltered method set spikes had many more compounds with low variability and low bias compared to the unfiltered method low-level and high-level spikes. Only four compounds (chloroxylenol, griseofulvin, iminostilbene, and phenobarbital) had low bias and low variability for the set spikes as well as the low-level and high-level spikes.

The remaining 20 compounds with low bias and low variability for the set spikes generally either had high mean recoveries for the low-level spikes or had high RSDs for the high-level spikes. Some of these compounds Of the 20 compounsd with low bias and low variability for the set spikes, 10 (butalbital, chirald, dextromethorphan, diazepam, diltiazem, efavirenz, methadone, pentobarbital, piperonyl butoxide, and ticlopidine) had high median recoveries for the low-level spikes (133171 percent). Mean recoveries for the high-level spikes for these 10 compounds ranged from 90 to 119 percent. RSDs for both the low-level and high-level spikes for these 10 compounds generally were low $(<30$ percent).

Of the compounds with low bias and low variability for the set spikes had high RSDs for the high-level spikes (31-59 percent), twelve (antipyrine, chirald, chlorpheniramine, citalopram, diltiazem, lidocaine, meperidine, meprobamate, methylphenidate, pentoxifylline, phendimetrazine, and propofol) had mean spike recoveries for the low-level and high-level spike experiments similar to those for the set spikes, and low (<28 percent) RSDs.

The remaining 22 compounds had high bias, high variability or both for the set spikes, and generally had poor performance for the low-level and high-level spikes. The 10 compounds (2-ethyl-2phenylmalonamide, codeine, dihydrocodeine, hydrocodone, methocarbamol, norpropoxyphene, oxacarbazepine, oxycodone, primidone, and venlafaxine) in this group with low mean set spike recoveries ( $<59$ percent) generally had low recoveries ( $<50$ percent) for the high-level spikes (codeine and dihydrocodeine were the exceptions with mean recoveries of 72 and 65 percent, respectively). The 14 compounds (amitriptyline, carbamazepine, carisoprodol, celecoxib, codiene, dihydrocodeine, diphenhydramine, fluconazole, ibuprofen, metaxalone, phenytoin, temazepam, tramadol, and verapamil) that had high RSDs (34-57 percent) for the unfiltered set spikes generally had high RSDs (3146 percent) for the high-level spikes. Some compounds (carbamazepine and phenytoin) had poorer performance for the set spikes than for the low-level and high-level spikes for the unfiltered method. These two compounds had low bias and low variability for the low-level spikes and the high-level spikes, but high RSDs ( $>38$ percent) for the set spikes. 
As with the filtered method, the causes of the poor performance for the low-level and high-level spike experiments compared to the set spike recoveries are not clear for the unfiltered results. The cause of the relatively low recoveries for the reagent low-level and high-level spike experiments compared to the reagent set spike recoveries is not clear. As explained in detail in the 'Filtered Method' section, a possible explanation for the low recoveries in the reagent-spike validation samples is that there were a greater number of active (sorptive) sites in the GC inlet and column during analyses of the validation samples compared with the GC conditions during analyses of the set spike samples. As with the filtered method, because relatively few analyses were performed for the reagent low- and high-level spike experiments (7) compared to the number of set spike analyses (34), the lower reagent experiment recoveries for the unfiltered method could be due to anomalous conditions that occurred during this experiment. Overall, the large number of samples and longer time period of the set spike results indicate that these results are more representative of unfiltered method performance in reagent water than the reagent spike experiments.

\section{Set Blank Results}

Potential for contamination during extraction and analysis was assessed through set blanks. Set blank samples were prepared using the same materials and reagents as environmental samples. Set blanks are prepared using reagent water, and are expected to be free of all analytes; thus, these samples are used to indicate the possibility of any laboratory-introduced contamination. At least one set blank is analyzed with each set of as many as 10 and 18 environmental samples for the filtered water and unfiltered water methods, respectively. With one exception, none of the analytes were detected in the set blanks for the filtered $(n=54)$ or unfiltered methods $(n=34)$ between 2010-11. The only exception was for oxycodone, which was detected in one of the unfiltered set blanks at a concentration of $0.1 \mu \mathrm{g}$.

\section{Method Detection Limits}

Method detection limits (MDLs) were determined according to the procedure outlined by the U.S. Environmental Protection Agency (2010) using a 1-L sample size. The MDL is defined as the minimum concentration of a substance that can be measured and reported with 99-percent confidence that the compound concentration is greater than zero (Timme, 1995). Separate MDLs were computed for surface water and wastewater for both the filtered and unfiltered methods. The use of surface water and wastewater in the current study for determining MDLs ensures that the MDLs for the current study are more applicable to types of water analyzed using the current method than those calculated in the 2010 study, because the 2010 study MDLs were based on spikes in reagent water. The MDLs (tables 11 and 12 for filtered and unfiltered samples, respectively) were calculated using eight spike replicates from each matrix.

Table 11. Method detection limits for compounds for filtered water analysis, in micrograms per liter.

Table 12. Method detection limits for compounds for unfiltered water analysis, in micrograms per liter.

MDLs ranged from 0.007 to $0.14 \mu \mathrm{g} / \mathrm{L}$ for the surface water matrix and from 0.004 to $0.62 \mu \mathrm{g} / \mathrm{L}$ for the wastewater matrix for the filtered method (table 11). MDLs ranged from 0.014 to $0.33 \mu \mathrm{g} / \mathrm{L}$ for the surface water matrix and from 0.008 to $0.36 \mu \mathrm{g} / \mathrm{L}$ for the wastewater matrix for the unfiltered method (table 12). 


\section{Qualification of Results}

In some instances, concentrations of some compounds have less certainty based on poor method performance. Concentrations for compounds with low bias and low variability for low-level and highlevel matrix spikes, as well as set spikes, for a given method should be considered acceptable; however, concentration data for compounds with high bias and (or) high variability for one or more of the lowlevel or high-level spikes for a given matrix, or poor set spike recovery, have less certainty and these data should be interpreted with caution.

\section{Concentrations in Surface Water for Filtered Method}

Eighteen compounds had low bias and low variability for the low-level and high-level surface water spikes, as well as the set spikes, for the filtered method (tables 3, 5). Surface-water concentrations analyzed by the filtered method for the remaining 24 compounds are classified as less certain due to high bias and (or) high variability for one or more of the set spikes, low-level surface water spikes, or high-level surface water spikes (table 3). Filtered surface water concentrations of three compounds (fluconazole, meprobamate, and primidone) are less certain due to poor performance for set spikes (table 5); low-level and high-level surface water spikes for these three compounds had low bias and variability. Surface water concentrations for nine of these compounds (butalbital, carisoprodol, chirald, methadone, methylphenidate, oxycodone, pentobarbital, temazepam, and tramadol) are less certain due to poor performance for low-level surface water spikes (table 3). Although these nine compounds generally had elevated recoveries for low-level surface water spikes, all nine compounds had low bias and variability for high-level surface water spikes and set spikes. Surface-water concentrations for the remaining 12 compounds (chlorpheniramine, citalopram, codeine, dihydrocodeine, diphenhydramine, hydrocodone, iminostilbene, meperidine, methocarbamol, oxacarbazepine, phendimetrizine, and propofol) are less certain based on poor method performance for two or more of the low-level surface water spikes, high-level surface water spikes, or set spikes (tables 3, 4).

\section{Concentrations in Wastewater for Filtered Method}

Twenty-three compounds had low bias and low variability for the low-level and high-level wastewater spikes, as well as the set spikes, for the filtered method (tables 4, 5). Wastewater concentrations analyzed by the filtered method for the remaining 19 compounds had less certainty due to high bias and (or) high variability for one or more of the set spikes, low-level wastewater spikes, or high-level wastewater spikes. Wastewater concentrations for one compound (meprobamate) are less certain due to high variability for set spikes. Wastewater concentrations analyzed by the filtered method are less certain for three compounds (phenobarbital, temazepam, and verapamil) due to high mean recoveries or high RSDs for the low-level surface-water spikes. Wastewater concentrations analyzed by the filtered method are less certain for seven compounds (citalopram, codeine, diphenhydramine, hydrocodone, iminostilbene, meperidine, and methadone) due to low recoveries for high-level wastewater spikes. Most of these compounds (citalopram, codeine, diphenhydramine, hydrocodone, meperidine, and methadone) have high-level wastewater spike recoveries between 55 and 58 percent, indicating a slight negative bias. All seven of these compounds had low variability for high-level spikes, and low bias and low variability for low-level wastewater spikes and set spikes. Wastewater concentrations analyzed by the filtered method are less certain for the remaining eight compounds (chlorpheniramine, dihydrocodeine, fluconazole, methocarbamol, oxacarbazepine, phendimetrizine, primidone, and propofol) due to high bias and (or) high variability for two or more of the low-level and high-level wastewater spikes and (or) the set spikes. 


\section{Concentrations in Surface Water for Unfiltered Method}

Ten compounds had low bias and low variability for the low-level and high-level surface water spikes, as well as the set spikes, for the unfiltered method (tables 7, 9). Surface water concentrations for the remaining 36 compounds are considered less reliable for the unfiltered method. Unfiltered surface water concentrations of seven compounds (carbamazepine, fluconazole, hydrocodone, ibuprofen, metaxalone, phenytoin, and tramadol) are considered less reliable due to poor performance for set spikes (table 9); low-level and high-level surface water spikes for these seven compounds had low bias and variability for the unfiltered method (table 7). Unfiltered surface water concentrations for 13 compounds (antipyrine, butalbital, chirald, chloroxylenol, chlorpheniramine, citalopram, efavirenz, methadone, methylphenidate, pentobarbital, pentoxifylline, piperonyl butoxide, and ticlopidine) are considered less reliable due to poor performance for low-level surface water spikes. Although these 13 compounds had elevated ( $>132$ percent) or low ( $<44$ percent) recoveries for low-level surface water spikes, all 13 compounds had low bias and low variability for high-level surface water spikes and set spikes (table 7). Unfiltered surface-water concentrations for the remaining 16 compounds (2-ethyl-2phenylmalonamide, amitriptyline, carisoprodol, celecoxib, codeine, dihydrocodeine, diltiazem, diphenhydramine, methocarbamol, norpropoxyphene, oxacarbazepine, oxycodone, primidone, temazepam, venlafaxine, and verapamil) are considered less certain based on poor method performance for two or more of the set spikes, low-level surface water spikes, and high-level surface water spikes (tables 7,9).

\section{Concentrations in Wastewater for Unfiltered Method}

Nine compounds had low bias and low variability for the low-level and high-level wastewater spikes as well as the set spikes for the unfiltered method (tables 8,9). Wastewater concentrations for the remaining 37 compounds are considered less reliable for the unfiltered method. Unfiltered wastewater concentrations are less reliable for five compounds (amitriptyline, carbamazepine, fluconazole, metaxalone, and tramadol) due to high variability (RSDs $>35$ percent) for set spikes; these compounds had low bias and low variability for the low-level and high-level wastewater spikes. Unfiltered wastewater concentrations for 14 of these compounds (antipyrine, chirald, chlorpheniramine, diazepam, diltiazem, efavirenz, griseofulvin, iminostilbene, methadone, pentobarbital, pentoxifylline, piperonyl butoxide, propofol, and ticlopidine) are considered less reliable due to poor performance for low-level wastewater spikes. In general, these 14 compounds had elevated mean recoveries ( $>130$ percent) for low-level surface water spikes, but two (iminostilebene and propofol) had high variability (RSDs $>33$ percent) for the low-level surface-water spikes. All 14 of these compounds had low bias and low variability for high-level surface water spikes and set spikes. Unfiltered wastewater concentrations are considered less reliable for methylphenidate due to low recovery ( 53 percent) for the high-level wastewater spikes; this compound had low bias and low variability for the low-level wastewater and set spikes. Unfiltered wastewater concentrations for the remaining 17 compounds (2-ethyl-2phenylmalonamide, carisoprodol, celecoxib, codeine, dihydrocodeine, diphenhydramine, hydrocodone, ibuprofen, methocarbamol, norpropoxyphene, oxacarbazepine, oxycodone, phenytoin, primidone, temazepam, venlafaxine, and verapamil) are considered less reliable based on poor method performance for one or more of the set spikes, low-level wastewater spikes, and high-level wastewater spikes. 


\section{Environmental Concentrations of Compounds}

Concentrations for select wastewater and surface water samples analyzed using the filtered method are shown in table 13. Concentrations for select wastewater and surface water and samples analyzed using the unfiltered method are shown in table 14.

Table 13. Concentrations for compounds for filtered method in samples from a stream site below the effluent discharge (site NY1D) and samples of effluent from a wastewater-treatment plant (site NY1E), collected between September 2010 and May 2011.

Table 14. Concentrations for compounds for unfiltered method in five stream samples and samples of effluent from three wastewater-treatment plants, collected in October and November 2011, and December 2009, respectively.

The surface water samples analyzed using the filtered method were collected from a stream site (site code NY1D) located $30 \mathrm{~m}$ below the discharge of the NY1E, effluent between September 2010 and May 2011 (table 13). Seventeen $(n=17)$ compounds were detected in at least one surface water sample analyzed using the filtered method, with a maximum concentration of $1.8 \mu \mathrm{g} / \mathrm{L}$.

Wastewater samples analyzed using the filtered method were collected from a WWTP (site code NY1E) in southeastern New York between September 2010 and April 2011 (table 13). The wastewater samples also include a replicate and an equipment blank sample. Thirty compounds were detected in at least one of the wastewater samples analyzed using the filtered method, with a maximum concentration of $0.87 \mu \mathrm{g} / \mathrm{L}$. No compounds were detected in the blank sample. The median percent difference for the 18 compounds with detections in both the environmental sample and the replicate was 15 percent, and most ( 75 percent) of these differences were $<40$ percent.

The surface water samples analyzed using the unfiltered method were collected from five stream sites ( site code IAS1, IAS2, IAS3, IAS4, and IAS5) in central Iowa in October and November 2011. Twenty-seven $(n=27)$ compounds were detected in at least one surface water sample analyzed using the unfiltered method, with a maximum concentration of $0.64 \mu \mathrm{g} / \mathrm{L}$.

The wastewater samples analyzed using the unfiltered method were collected from three different WWTPs (site code OR1E, OR2E, and OR3E) in Oregon in December 2009. The wastewater samples include a replicate sample for site OR2E. Thirty compounds were detected in at least one of the wastewater samples analyzed using the unfiltered method, with a maximum concentration of $6.4 \mu \mathrm{g} / \mathrm{L}$. The median percent difference for the 18 compounds with detections in both the environmental sample and the replicate was 34 percent, and most ( 75 percent) of these differences were $<45$ percent.

\section{Summary}

The effects of low-level exposure of stream biota to complex mixtures of pharmaceuticals and other organic compounds associated with wastewater are poorly understood. Studies have shown a range of potential adverse biologic effects of low concentrations of pharmaceuticals that are present in surface waters. These adverse effects include acute and chronic toxicity, accumulation in tissues, reproductive effects, altered fish behavior, changes in growth, and other effects. Recent identification of a wide range of pharmaceuticals and other organic compounds in samples collected from wastewater treatment plants suggest the need for development of analytical methods for additional pharmaceutical compounds that may be present in wastewater effluent. For example, high concentrations of pharmaceuticals from discharges by pharmaceutical production facilities have been linked to reduced growth, adverse physiological changes, lethal effects in fish, masculinization of fish, and physiological 
effects on invertebrates. Continued research is needed to identify and quantify pharmaceuticals discharged to aquatic environments, so that the potential effect of these pharmaceuticals on the health of stream ecosystems can be better understood. This research requires the development of additional analytical capabilities for water samples that include pharmaceuticals and other compounds.

Two gas chromatography/mass spectrometry (GC/MS) analytical methods used at the U.S. Geological Survey National Water Quality Laboratory (NWQL) to analyze organic compounds associated with wastewater were adapted to include additional pharmaceutical and other organic compounds beginning in 2009. These two methods have been used at the NWQL for the analysis of these compounds in diverse matrices ranging from groundwater, surface water, and influent and effluent wastewater treatment. The first method is suitable for filtered water samples and uses solid-phase extraction, and the second method is suitable for unfiltered water samples and uses continuous liquidliquid extraction. The compounds of interest for filtered and unfiltered sample types were determined by use of the capillary-column gas chromatography and mass spectrometry. The filtered-water method (hereafter referred to as the filtered method) includes analysis of 42 compounds, and the unfilteredwater method (hereafter referred to as the unfiltered method) includes analysis of 46 compounds. Nearly all of these compounds are pharmaceuticals or pharmaceutical degradates, however two nonpharmaceutical compounds are included in each method.

Method performance assessment for these compounds is largely based on data on recoveries of compounds in fortified surface-water, wastewater, and reagent-water samples. These experiments (referred to as spike experiments) consist of fortifying (or spiking) samples with known amounts of target analytes. Surface-water-spike experiments were performed for the unfiltered method using samples obtained from Colorado and for the filtered method using samples obtained from a stream in New York (filtered method). Wastewater spike experiments for both the filtered and unfiltered methods were performed using a treated wastewater obtained from a single wastewater treatment plant in New York. Surface water and wastewater spike experiments were fortified at both low-concentration and high-concentration levels (hereafter referred to as low- and high-level spikes). Three types of reagentwater spikes were used to assess method performance: (1) set spikes, (2) a low-concentration fortification experiment, and (3) a high-concentration fortification experiment. Set spike samples consist of analysis of fortified reagent water for target compounds included for each group of 10 to 18 environmental samples analyzed at the NWQL. The low-concentration and high-concentration reagent spike experiments, by contrast, represent a one-time assessment of method performance. For all spike experiments, mean recoveries ranging from 60 to 130 percent indicate low bias, and relative standard deviations (RSDs) less than $(<) 30$ percent indicate low variability.

Twenty-one of the compounds included in the filtered method had recoveries ranging from 63 to 129 percent for the low- and high-level surface water spikes, and had low relative standard deviations (RSDs; less than $[<] 15$ percent) for both spike experiments. The remaining 21 compounds generally have high bias for the low-level experiment and (or) the high-level spike experiment (mean recoveries $<58$ or greater than $[>] 132$ percent).

Twenty-four of the compounds included in the filtered method had recoveries ranging from 61 to 130 percent for the low-level and high-level wastewater spikes. RSDs were $<29$ percent for both of these spike experiments for these compounds. The remaining 18 compounds in the filtered method generally had high bias or variable recoveries for low-level wastewater spikes or low recoveries for high-level wastewater spikes. Three compounds had high recoveries ( $>136$ percent) or high variability (RSDs $>32$ percent) for the low-level wastewater spikes. Eleven compounds had low mean recoveries $(<58$ percent) for the high-level wastewater spikes. The remaining four compounds had low $(<59$ percent $)$ mean recoveries for both low-level and high-level spikes. 
Thirty-four of the compounds included in the filtered method had mean set spike recoveries between 61 and 126 percent, and RSDs $<29$ percent. The remaining 8 compounds either had low mean recoveries ( $<59$ percent) or high RSDS ( $>34$ percent) for set spikes. Method performance for reagent low-level and high-level spikes was not as good, because only 14 of the compounds had mean recoveries ranging from 71 to 129 percent, and RSDs $<24$ percent. Overall, the large number of samples and longer time period of the set spike results indicate that these results are more representative of method performance in reagent water than the low-level and high-level reagent spike experiments.

Seventeen of the compounds included in the unfiltered method had mean spike recoveries ranging from 74 to 129 percent and RSDs between 5 and 25 percent for low-level and high-level surface water spikes. Twenty-two compounds had high ( $>132$ percent) or low (44 percent) mean recoveries for low-level spike recoveries, or high RSDs ( $>29$ percent) for these spikes. Two compounds had low mean recoveries ( $<49$ percent) for the high-level surface water spikes. The remaining five compounds had high bias for both the low-level and high-level surface water spikes.

Fourteen of the compounds included in the unfiltered method had mean recoveries ranging from 62 to 127 percent and low RSDs ( $<25$ percent) for the low-level and high-level wastewater spikes. Twenty compounds had poor performance for the low-level wastewater spikes. Most of these compounds had high mean recoveries ( $>132$ percent), and some had low mean recoveries ( $<20$ percent) or high RSDs ( $>33$ percent) for the low-level wastewater spikes. Four compounds had low mean recoveries $(<59$ percent) for the high-level wastewater spikes. Eight compounds had poor recoveries ( $<54$ or $>155$ percent) for high-level wastewater spikes and poor recoveries ( $<50$ or $>170$ percent) or variable recoveries (RSD $>70$ percent) for the low-level wastewater spikes.

Twenty-four of the compounds had mean set spike recoveries ranging from 64 to 104 percent and RSDs $<30$ percent for the unfiltered method. The remaining 22 compounds had low mean recoveries or high RSDs for the set spikes. Method performance for reagent low-level and high-level spikes for the unfiltered method was not as good as for the reagent set spikes. Six of the compounds had mean recoveries ranging from 66 to 130 percent and RSDs $<30$ percent for both the low-level and highlevel reagent spikes. The remaining 40 compounds had poor recoveries for the low-level reagent spikes and (or) the high-level reagent spikes, or had high RSDs ( $>29$ percent) for these spikes. As with the filtered method, the large number of samples and longer time period of the set spike results indicate that these results are more representative of method performance in reagent water than the low-level and high-level reagent spike experiments.

Separate method detection limits (MDLs) were computed for surface water and wastewater for both the filtered and unfiltered methods. MDLs ranged from 0.007 to 0.14 microgram per liter $(\mu \mathrm{g} / \mathrm{L})$ for the surface water matrix and from 0.004 to $0.62 \mu \mathrm{g} / \mathrm{L}$ for the wastewater matrix for the filtered method. MDLs ranged from 0.014 to $0.33 \mu \mathrm{g} / \mathrm{L}$ for the surface water matrix and from 0.008 to $0.36 \mu \mathrm{g} / \mathrm{L}$ for the wastewater matrix for the unfiltered method.

\section{Acknowledgments}

The authors wish to acknowledge and thank reviewers, including Chad Kinney, University of Colorado, Kelly Smalling, U.S. Geological Survey, and John Zogorski, U.S. Geological Survey, for their thoughtful and thorough reviews of this manuscript. 


\section{References Cited}

Ashton, D., Hilton, M., and Thomas, K.V., 2004, Investigating the environmental transport of human pharmaceuticals to streams in the United Kingdom: Science of the Total Environment, v. 333, p. 167-184.

Bones, J., Thomas, K.V., and Paull, B., 2007, Using environmental analytical data to estimate levels of community consumption of illicit drugs and abused pharmaceuticals: Journal of Environmental Monitoring, v. 9, p. 701-707.

Brooks, B.W., Turner, P.K., Stanley, J.K., Weston, J.J., Glidewell, E.A., Foran, C.M., Slattery, M., La Point, T.W., and Huggett, D.B., 2003, Waterborne and sediment toxicity of fluoxetine to select organisms: Chemosphere, v. 52, p. 135-142.

Bruchet, A., Hochereau, C., Picard, C., Decottignies, V., Rodrigues, J.M., and Janex-Habibi, M.L., 2005, Analysis of drugs and personal care products in French source and drinking waters-The analytical challenge and examples of application: Water Science and Technology, v. 52, p. 53-61.

Carlsson, G., Örn, S., and Larsson, D.G.J., 2009, Effluent from bulk drug production is toxic to aquatic vertebrates: Environmental Toxicology and Chemistry, v. 28, p. 2656-2662.

Castiglioni, S., Zuccato, E., Crisci, E., Chiabrando, C., Fanelli, R., and Bagnati, R., 2006, Identification and measurement of illicit drugs and their metabolites in urban wastewater by liquid chromatographytandem mass spectrometry: Analytical Chemistry, v. 78, p. 8421-8429.

Clara, M., Strenn, B., Gans, O., Martinez, E., Kreuzinger, N., and Kroiss, H., 2005, Removal of selected pharmaceuticals, fragrances and endocrine disrupting compounds in a membrane bioreactor and conventional wastewater treatment plants: Water Research, v. 39, p. 4797-4807.

Crane, M., Watts, C., and Boucard, T., 2006, Chronic aquatic environmental risks from exposure to human pharmaceuticals: Science of the Total Environment, v. 367, p. 23-41.

Erney, D.R., Gillepsie, A.M., and Gilvydis, D., 1993, Explanation of the matrix-induced chromatographic response enhancement of organophosphorus pesticides during open tubular column gas chromatography with splitless or hot on-column injection and flame photometric detection: Journal of Chromatography A, v. 638, no. 1, p. 57-63.

Fick, J., Soderstrom, H., Lindberg, R., Phan, C., Tysklind, M., and Larsson, D., 2009, Contamination of surface, ground, and drinking water from pharmaceutical production: Environmental Toxicology and Chemistry, v. 28, p. 2522-2527.

Glassmeyer, S.T., Furlong, E.T., Kolpin, D.W., Cahill, J.D., Zaugg, S.D., Werner, S.L., Meyer, M.T., and Kryak, D.D., 2005, Transport of chemical and microbial compounds from known wastewater discharges - Potential for use as indicators of human fecal contamination: Environmental Science and Technology, v. 39, no. 14, p. 5157-5169.

Gunnarsson, L., Kristiansson, E., Rutgersson, C., Sturve, J., Fick, J., Förlin, L., and Larsson, D.G.J., 2009, Pharmaceutical industry effluent diluted 1:500 affects global gene expression, cytochrome P450 1A activity, and plasma phosphate in fish: Environmental Toxicology and Chemistry, v. 28, p. 26392647.

Hummel, D., Loffler, D., Fink, G., and Ternes, T., 2006, Simultaneous determination of psychoactive drugs and their metabolites in aqueous matrices by liquid chromatography mass spectrometry: Environmental Science and Technology, v. 40, p. 7321-7328.

Kim, S.D., Cho, J., Kim, I.S., Vanderford, B.J., and Snyder, S.A., 2007, Occurrence and removal of pharmaceutical and endocrine disruptors in South Korean surface, drinking, and waste waters: Water Research, v. 41, p. 1013-1021.

Kolpin, D.W., Furlong, E.T., Meyer, M.T., Thurman, E.M., Zaugg, S.D., Barber, L.B., and Buxton, H.T., 2002, Pharmaceuticals, hormones, and other organic wastewater contaminants in 35 U.S. 
Streams, 1999-2000-A National Reconnaissance: Environmental Science and Technology, v. 36, p. $1202-1211$.

Langford, K.H., and Thomas, K.V., 2009, Determination of pharmaceutical compounds in hospital effluents and their contribution to wastewater treatment works: Environment International, v. 35, p. 766-770.

Larsson, D.G., de Pedro, C., and Paxeus, N., 2007, Effluent from drug manufactures contains extremely high levels of pharmaceuticals: Journal of Hazardous Materials, v. 30, p. 751-755.

Lin, A., Yu, T., and Lin, C., 2008, Pharmaceutical contamination in residential, industrial, and agricultural waste streams: Risk to aqueous environments in Taiwan: Chemosphere, v. 74, p. 131141.

Nentwig, G., 2007, Effects of pharmaceuticals on aquatic invertebrates-Part II: The antidepressant drug fluoxetine: Archives of Environmental Contamination and Toxicology, v. 52, p. 163-167.

Painter, M.M., Buerkley, M.A., Julius, M.L., Vajda, A.M., Norrris, D.O., Barber, L.R., Furlong, E.T., Schultz, M.M., and Schoenfuss, H.L., 2009, Antidepressants at environmentally relevant concentrations affect predator avoidance behaviours of larveal fathead minnows (Pimpehales Promelas): Environmental Toxicology and Chemistry, v. 28, p. 2677-2684.

Paterson, G., and Metcalfe, C.D., 2008, Uptake and depuration of the anti-depressant fluoxetine by the Japanese medaka (Oryzias latipes): Chemosphere, v. 74, p. 125-130.

Peschka, M., Eubeler, J.P., and Knepper, T.P., 2006, Occurrence and fate of barbiturates in the aquatic environment: Environmental Science and Technology, v. 40, p. 7200-7206.

Pharmacy Times, 2011, Top 200 drugs of 2010: accessed February 3, 2012, at http://www.pharmacytimes.com/issue/pharmacy/2011/May2011/Top-200-Drugs-of-2010.

Phillips, P.J., Smith, S.G., Kolpin, D.W., Zaugg, S.D., Buxton, H.T., Furlong, E.T., Esposito, K., and Stinson, B., 2010a, Opiods, muscle relaxants, and other pharmaceuticals in wastewater-treatmentplant effluents, including plants receiving pharmaceutical manufacturing facility discharges:

Environmental Science and Technology, v. 44, p. 4910-4916.

Phillips, P.J., Smith, S.G., Kolpin, D.W., Zaugg, S.D., Buxton, H.T., and Furlong, E.T., 2010b, Method description, quality assurance, environmental data, and other information for analysis of pharmaceuticals in wastewater-treatment-plant effluents, streamwater, and reservoirs, 2004-2009: U.S. Geological Survey Open-File Report 2010-1102, 36 p., accessed February 3, 2012, at http://pubs.usgs.gov/of/2010/1102/.

Pomati, F., Castiglioni, S., Zuccato, E., Fanelli, R., Vigetti, D., Rossetti, C., and Calamari, D., 2006, Effects of a complex mixture of therapeutic drugs at environmental levels on human embryonic cells: Environmental Science and Technology, v. 40, p. 2442-2447.

Quinn, B., Gagne, F., and Blaise, C., 2008, An investigation into the acute and chronic toxicity of eleven pharmaceuticals (and their solvents) found in wastewater effluent on the cnidarian, Hydra attenuate: Science of the Total Environment, v. 389, p. 306-314.

Sanchez, W., Sremski, W., Piccini, B., Palluel, O., Maillot-Marechal, E., Betoulle, S., Jaffal, A., AitAissa, S., Brion, F., Thybaud, E., Hinfray, N., and Porcher, J-M., 2011, Adverse effects in wild fish living downstream from pharmaceutical manufacture discharges: Environment International, v. 37, p. $1342-1348$.

Schultz, M., Painter, M., Bartell, S., Logue, A., Furlong, E., Warner, S., and Schoenfuss, H., 2011, Selective uptake and biological consequences of environmentally relevant antidepressant pharmaceutical exposures on male fathead minnows: Aquatic Toxicology, v. 104, p. 38-104. 
Soliman, M.A., Pedersen, J.A., Park, J., Castaneda-Jiminez, A., Stenstrom, J.K., and Suffet, I.H., 2007, Human pharmaceuticals, antioxidants, and plasticizers in wastewater treatment plant and water reclamation plant effluents: Water Environment Research, v. 79, p. 156-167.

Timme, P.J., 1995, National Water Quality Laboratory 1995 services catalog: U.S. Geological Survey Open-File Report 95-352, $92 \mathrm{p}$.

U.S. Environmental Protection Agency, 2010, Guidelines establishing test procedures for the analysis of pollutants (App. B, Part 136, Definition and procedures for the determination of the method detection limit—Revision 1.11): U.S. Code of Federal Regulations, Title 40, accessed October 2013, at http://www.gpo.gov/fdsys/pkg/FR-2010-09-23/pdf/2010-20018.pdf.

Vanderford, B.J., and Snyder, S.A., 2006, Analysis of pharmaceuticals in water by isotope dilution liquid chromatography/tandem mass spectrometry: Environmental Science and Technology, v. 40, p. 7212-7320.

Vieno, N., Tuhkanen, T., and Kronberg, L., 2007, Elimination of pharmaceuticals in sewage treatment plants in Finland: Water Research, v. 41, p. 1001-1012.

Wilde, F.D., Radtke, D.B., Gibs, Jacob, and Iwatsubo, R.T., 2004, with updates through 2009, Processing of water samples (version 2.2): U.S. Geological Survey Techniques of Water-Resources Investigations, book 9, chap. A5, accessed October 23, 2012, at http://pubs.water.usgs.gov/twri9A5/. Zaugg, S.D., Smith, S.G., and Schroeder, M.P., 2006, Determination of wastewater compounds in whole water by continuous liquid-liquid extraction and capillary-column gas chromatography/mass spectrometry: U.S. Geological Survey Techniques and Methods, book 5, chap. B4, 30 p.

Zaugg, S.D., Smith, S.G., Schroeder, M.P., Barber, L.B., and Burkhardt, M.R., 2002, Methods of analysis by the U.S. Geological Survey National Water Quality Laboratory-Determination of wastewater compounds by polystyrene-divinylbenzene solid-phase extraction and capillary-column gas chromatography/mass spectrometry: U.S. Geological Survey Water-Resources Investigations Report 01-4186, $37 \mathrm{p}$. 
For more information concerning this report, contact

Director

U.S. Geological Survey

New York Water Science Center

425 Jordan Road

Troy, NY 12180-8349

dc_ny@usgs.gov

or visit our Web site at:

http://hy.water.usgs.gov 
